\title{
LAS OTRAS RAQUEL: EL DIÁLOGO TRÁGICO DE JOSÉ MARCH Y BORRÁS
}

\section{The others Raquel: the Diálogo trágico of José March y Borrás}

\author{
Jesús CAÑAS MURILLO \\ Universidad de Extremadura \\ jcanas@unex.es
}

Fecha de recepción: 21/02/2018

Fecha de aceptación definitiva: 20/04/2018

\begin{abstract}
RESUMEN: Se estudia en este artículo otro texto dedicado a tratar el tema dramático tradicional de la leyenda de Raquel, la judía de Toledo de la que el rey castellano Alfonso VIII supuestamente se enamoró: el Diálogo trágico. Intitulado La Raquel. Facil de egecutar en casas particulares. Sacado de la bistoria y adornado con intervalos de música. Por un aficionado, escrito por el castellonense José March y Borrás, una obra no muy conocida hasta la actualidad, y no citada entre las creaciones que históricamente se ocuparon de esos mismos asuntos. En el trabajo se encuadra el Diálogo trágico en la tradición dramática en la que se inserta; se identifica el grupo de obras de la Ilustración al que pertenece y el género que le es propio; se proporcionan los datos que se conservan sobre su desconocido autor; se estudia la composición recibida por el mismo; se rescatan datos sobre los impresores que lo dieron a conocer en su siglo; y se efectúa una edición moderna de él, con el fin de ponerlo así al alcance de los lectores interesados. Con todo, se ha pretendido contribuir a rescatar una parte importante del patrimonio bibliográfico español, que hasta ahora ha permanecido en la sombra, y completar, de tal modo, el panorama habitualmente presentado de la cultura y la literatura españolas de la era de la Ilustración.
\end{abstract}

Palabras clave: historia literaria; siglo XVIII español; ilustración; teatro; tragedia neoclásica española; la leyenda de Raquel; José March y Borrás. 
ABSTRACT: This paper deal with another text dedicated to treat with the traditional dramatic theme of the legend of Raquel, the Jewish of Toledo of which the Castilian King Alfonso VIII supposedly fell in love: Diálogo trágico. Intitulado La Raquel. Facil de egecutar en casas particulares. Sacado de la historia y adornado con intervalos de música. Por un aficionado, written by the Castellón-born José March y Borrás, a work not well known until the present, and not mentioned between the creations that historically dealt with those same issues. In this article, the Diálogo trágico is framed in the dramatic tradition in which it is inserted; it is dentified the group of works of the Enlightenment to which it belongs, and the historic literary genre that is its own; the data that is preserved about its unknown author is provided; the composition received by the same is studied; information are rescued about the printers who made it known in their century; and a modern edition of it is made, in order to make it available to interested readers. With everything, it has been tried to contribute to rescue an important part of Spanish bibliographical heritage, that, until now, it has remained in the shade, and to complete, in this way, the usually presented panorama of the Spanish culture and Literature of the age of the Enlightenment.

Key words: literary history; Spanish 18th century; enlightenment; theater; Spanish neoclassical tragedy; the legend of Raquel; José March y Borrás.

\section{La leyenda de la Judía de Toledo en el teatro}

La leyenda de los amores del rey Alfonso VIII de Castilla, el vencedor en las Navas de Tolosa, con una judía de Toledo, llamada Fermosa en la Primera Crónica General, o Estoria de España, de Alfonso X el Sabio ${ }^{1}$, y bautizada como Raquel por Lope de Vega -el primer autor español que se ocupó de ella en el teatro-, en su obra Las paces de los Reyes y Judía de Toledo ${ }^{2}$, nombre con el que pasó a la posteridad, tuvo un amplio tratamiento en la historia del teatro español desde el siglo XVII hasta el siglo XX.

La leyenda se suele considerar ficticia, sin base real comprobable documentalmente. Ya en el siglo XVIII lo afirmó categóricamente el intelectual Joaquín Ezquerra, catedrático de Lengua Latina en los Reales Estudios de San Isidro de Madrid, en su capítulo dedicado a "Don Alfonso VIII, Rey de Castilla, y Don Alfonso IX, Rey de León", incluido en los Retratos de los Reyes de España ${ }^{3}$, promovidos y

1. El texto de la Primera Crónica General, o Estoria de España, alfonsí que se hace eco de la leyenda de Raquel, es recogido en el tomo IV de la obra de MenÉndez Pelayo, Marcelino. Estudios sobre el teatro de Lope de Vega. Edición de Enrique Sánchez Reyes. Santander: CSIC, 1949, pp. 79-91, dentro del comentario dedicado a "Las Paces de los Reyes y Judía de Toledo" (pp. 79-106).

2. Cf. Cañas Murillo, Jesús. "Las paces de los reyes y Judía de Toledo, de Lope de Vega, un primer preludio de Raquel». Anuario de Estudios Filológicos, 1988, XI, pp. 59-81.

3. Retratos de los Reyes de España desde Atanarico basta nuestro Católico Monarca Don Cárlos III (que Dios guarde). Segun las noticias y los Originales mas antiguos que se han hallado, con sus 
coordinados por Manuel Rodríguez, "Academico Supernumerario de la Real Academia de S. Fernando, Grabador de láminas y sellos»-como se indica en la portada de los tomos, y a quien se deben también los grabados de los monarcas incluidos en los volúmenes-. Los Retratos, como expliqué en otro lugar ${ }^{4}$, fueron redactados primero por Vicente García de la Huerta, y, al producirse el fallecimiento de este, por el mencionado Joaquín Ezquerra hasta la conclusión de la obra. No obstante, los escritores, desde el ya citado Lope de Vega, la consideraron una excelente materia para construir obras dramáticas, y la convirtieron, como indicamos, en fecundo asunto de amplia trayectoria histórica, y de constante tratamiento durante largo tiempo, en el teatro español.

Tras el Fénix de los Ingenios, muchos comediógrafos desearon abordar en sus textos el drama de Raquel. Así, Antonio Mira de Amescua, en su obra La desgraciada Raquel, de 1625; Juan Bautista Diamante, en La Judia de Toledo, publicada en 16675; Pedro Francisco Lanini Sagredo, en El rey don Alfonso el Bueno, de 1675, y en La batalla de las Navas y rey don Alfonso el Bueno, de 1701; Eusebio Asquerino, en La Judía de Toledo o Alfonso VIII, de 1842; Pedro Pardo de la Casta, en Raquel, o los amores de Alfonso VIII rey de Castilla, de 1859; Ángel Lasso de

correspondientes Inscripciones y el sumario de la vida de cada Rey. Publicalos para instrucción de la juventud española Don Manuel Rodriguez, Académico Supernumerario de la Real Academia de S. Fernando, Grabador de láminas y sellos. Edición de tres tomos en cuatro volúmenes. Tomo I, Madrid: s. i., 1782. Tomo I, Madrid: Joachîn Ibarra, 1782. Tomo II, Madrid: Lorenzo de San Martín, 1788. Tomo III "y último", Madrid: Lorenzo de San Martín, 1788. Parte II del Tomo III "y último de la obra", Madrid: Lorenzo de San Martín, 1790. Manuel Rodríguez es el editor de la obra, y el dibujante y grabador de los retratos. Vicente García de la Huerta elaboró los sumarios, las biografías de todos los reyes visigodos incluidos en el tomo primero de la serie y los sumarios de los reyes españoles desde Don Pelayo hasta Alfonso IV, ubicados en el tomo II de la colección entre las páginas 1-91. El resto de las biografías de los monarcas, desde Ramiro II hasta Carlos III, hechas tras la muerte del zafrense, fue obra del catedrático de Latín Joaquín Ezquerra (tomo II, pp. 95-286; y tomos III, 1 y III, 2). El capítulo dedicado a Alfonso VIII se incluye en el tomo II, pp. 265-268. La historia de los amores de Alfonso VIII con la judía de Toledo aparece debatida en un apéndice final añadido titulado "La Judía de Toledo", e inserto entre las páginas 282 y 286.

4. Cf. Cañas Murillo, Jesús de. "Vicente García de la Huerta y los Retratos de los Reyes de España: un problema bibliográfico y una aclaración”. eHumanista. Journal of Iberian Studies, 27, "Siglo ilustrado y siglo filosófico": cultura y letras hispánicas en el siglo XVIII». Ed. Franco Quinziano. University of California, Santa Barbara, California (Estados Unidos de América), 2014, pp. 89-168. (http://www.ehumanista.ucsb.edu/volumes/volume_27/pdf/special\%20volume/7\%20ehum27. canas. pdf); y "Un proyecto editorial: Los Retratos de los Reyes de España, de Manuel Rodríguez y Vicente García de la Huerta». En Cañas Murillo, Jesús; Lama, Miguel Ángel y Roso Díaz, José (eds.). Vicente García de la Huerta y su obra (1734-1787). Madrid: Visor Libros (Biblioteca Filológica Hispana, 170), 2015, pp. 187-290.

5. Según algunos críticos, esta obra no es sino la pieza de Mira de Amescua, cambiada de título, que sufre unas correcciones debidas a la censura y que fue indebidamente atribuida en la impresión a un autor incorrecto, el mencionado Juan Bautista Diamante. Cf. MARTín LARGO, José Ramón. La judía de Toledo, desde Lope de Vega hasta Franz Grillparzer. Prólogo de Ángel Gómez Moreno. Madrid: Brand Editorial, 2000, pp. 165-168. 
la Vega y Argüelles, en Raquel, de 1891; o Mariano Capdebón, en Raquel, cuya segunda edición fue impresa en 1891.

La más famosa de las piezas que trataron esta famosa historia de ficción fue la tragedia Raquel, compuesta por Vicente García de la Huerta, que recibió, tanto en su época como en la posteridad, amplio reconocimiento por parte del público y de la crítica por esta composición ${ }^{6}$. En este trabajo vamos a abordar otro texto más sobre el mismo asunto. Se trata de una creación que no ha sido reconocida por la historia, que no aparece citada en los estudios dedicados a la leyenda, de la que apenas hallamos referencias en trabajos de erudición y de investigación histórica y literaria. Nos referimos al Diálogo trágico. Intitulado La Raquel. Facil de egecutar en casas particulares. Sacado de la historia y adornado con intervalos de música. Por un aficionado.

\section{UN TEATRO PARA MINORÍAS}

El Diálogo trágico intitulado La Raquel pertenece a un grupo de obras al que la crítica no ha prestado todavía la atención que, sin duda, se merece. Se trata de textos breves, de extensión escasa, en cuyos argumentos se introducen pocos personajes, incluso, a veces, solo uno, de montaje sencillo, o no especialmente complejo, con pocos actores, e incluso con uno solo, con poco, y no especialmente lujoso, vestuario, con pocos decorados, ausentes de grandes cambios en estos en la representación, sin empleo de grandes efectos especiales. Son textos aptos para ser representados en casas particulares, sin que supusieran una gran merma en el patrimonio de la persona que había encargado el espectáculo, y que, en consecuencia, habría de sufragar todos los costes del mismo. Son las llamadas, en ocasiones, «escenas unipersonales», o comedias o dramas o tragedias «fáciles de representar en domicilios particulares». El destinatario de las mismas, su receptor, sería la clase alta, adinerada, del momento, como la nobleza o la incipiente burguesía de la Ilustración y sus invitados. Nos hallamos, en definitiva, ante un teatro para minorías, para pequeños grupos selectos de la población del momento, que

6. Cf. Cañas Murillo, Jesús; Lama, Miguel Ángel y Roso Díaz, José (eds.). Vicente García de la Huerta y su obra (1734-1787). Madrid: Visor Libros (Biblioteca Filológica Hispana, 170), 2015; GARCíA DE la HuerTa, Vicente. Raquel. Edición, introducción y notas de Jesús Cañas Murillo. Madrid: Bolchiro S. L., 2014; y García DE la HuerTa, Vicente. Teatro Completo. Edición crítica, introducción y notas de Jesús Cañas Murillo, en prensa en el Instituto Feijoo de Estudios del Siglo XVIII, de la Universidad de Oviedo; CaÑas Murillo, Jesús. La tragedia neoclásica española. Madrid: Ediciones Liceus (Aprendizaje Express, 1), 2017; CaÑas Murillo, Jesús. "Tipología de los personajes en las tragedias de Vicente García de la Huerta». En Simposio Internacional "Vicente García de la Huerta» (1787-1987). Edición de Jesús Cañas Murillo y Miguel Ángel Lama. Revista de Estudios Extremeños, mayo-agosto de 1988, XLIV, II, Badajoz: Servicio de Publicaciones de la Excma. Diputación Provincial, pp. 349-377; CaÑas Murillo, Jesús. "Raquel, de Vicente García de la Huerta, en la tragedia neoclásica española». Anuario de Estudios Filológicos, 2000, XXIII, pp. 9-36. 
acudían a presenciarlas no a locales públicos, sino a las residencias privadas de sus anfitriones, que eran los encargados de cursar las pertinentes invitaciones a sus amigos, allegados y conocidos, a los espectadores que habrían de presenciar la función ${ }^{7}$. Nos hallamos ante un teatro que podía ser utilizado como medio de entretener ciertas tardes de ocio, y amenizar veladas a las que solían los mencionados anfitriones invitar a sus amistades.

A este grupo de piezas, integrantes del teatro breve de la época ${ }^{8}$ y encuadrables en diferentes géneros, pertenecerían composiciones como Ariadna abandonada en Naxos. Melodrama en un acto, con periodos de música, impresa como anónima; el texto celebrativo y conmemorativo El Nuevo Apolo y Minerva. Drama, que se ha de representar en la fideli Ssima Ciudad de Cervera en celebridad del Transito del Rey Nuestro Señor Carlos Tercero, que Dios guarde, impreso como anónimo, y que en otro tiempo editamos'; Polixêna. Tragedia en un acto fácil de executarse en qualquiera casa particular, por estar arreglada para quatro personas, y entre ellas una sola muger, impresa como anónima, y que también editamos en otro trabajo nuestro ${ }^{10}$; el Melo-drama trágico en un acto Hercules y Deyanira. Compuesto por Don Luciano Francisco Comella ${ }^{11}$; Síquis y Cupido. Drama heroico en un acto. Por Don Luciano Francisco Comella; El rencor mas inbumano de un pecho aleve y tirano, o La Condesa Jenovitz. Comedia en tres actos, con su Loa. Funcion facil de egecutarse en cualquier casa particular por estar toda arreglada para cinco Personas, y entre ellas una sola muger, de José Concha ${ }^{12}$; el, así llamado, Drama nuevo. Juanito y Coleta ó El Pleyto del Marquesado. Comedia en tres actos. Pensamiento frances del celebre Mr. Florian. Acomodado a nuestro teatro por D. F. M. E. y C. Pieza facil de executar en casas particulares, de Félix Enciso y Castrillón ${ }^{13}$; la Comedia El amor filial. En dos actos. En verso. Fácil de executarse, quizá de Pablo Esteve ${ }^{14}$; la Pequeña, y breve comedia, titulada, Lances de amor, desdén y celos. Fácil de executar en cualquier casa particular por no tener mas que

7. Cf. CaÑas Murillo, Jesús. "Una "escena unipersonal” entre dos siglos: El Entretenido, ó La brevedad sin sustancia, de Manuel González”. En CAÑAS Murillo, Jesús. Cajón de sastre. Textos dispersos del setecientos español. Cáceres: Universidad de Extremadura (Textos UEx., 14), 2008, pp. $415-424$. Ver pp. 415-416. No es todo ello obstáculo para que algunas de esas composiciones pudieran ser, igualmente, representadas en algunos de los escenarios públicos de la época.

8. Véase, sobre el teatro breve español, HuerTa CALvo, Javier (ed.). Historia del teatro breve en España. Madrid-Frankfurt: Iberoamericana-Vervuert, 2008; y SALA-VAlLDAURA, Josep Maria. Caminos del teatro breve del siglo XVIII. Lérida: Universidad de Lérida-Pagès Editors, 2010.

9. Cf. CaÑas Murillo, Jesús. "Teatro celebrativo en honor de Carlos III: El Nuevo Apolo y Minerva». En Cajón de sastre, cit., pp. 401-414.

10. Cañas Murillo, Jesús. «Teatro neoclásico para representaciones particulares: Polixêna, tragedia en un acto, fácil de executarse». Anuario de Estudios Filológicos, 2010, XXXIII, pp. 39-63.

11. Barcelona: En la Oficina de Pablo Nadal, Calle del Torrente de Junqueras, Año de 1800.

12. Valencia: Imprenta de Ildefonso Mompié, 1816.

13. Madrid, Año 1799.

14. En Alcalá, Año de 1799. 
tres personas, de Antonio Furmento; El Entretenido, ó La brevedad sin sustancia. Escena unipersonal. Fácil de representarse en cualquier casa particular. Dispuesta en tres Jornadas, Entremés, dos Tonadillas y un Saynete, de Manuel González, de la que nos ocupamos en otra ocasión ${ }^{15}$; la tragedia Guzmán el Bueno, Escena trágica unipersonal, con música en sus intervalos, compuestas ambas por D. Tomás de Iriarte para representarse en Cadiz Por el Señor Luis Navarro, primer Actor de la Compañía Cómica ${ }^{16}$; Pigmalion. Monólogo patético, traducido y puesto en verso, por D. F. M. N., de Francisco Mariano Nipho ${ }^{17}$; el "Monólogo", como es denominado en el manuscrito que lo recoge, Policena, de Fermín del Rey ${ }^{18}$; la comedia popular El domingo, ó el cochero, Escena sola, monólogo, soliloquio, lamentacion, declamacion, ó llamese como quisiere, que á su autor le importa poco el nombre. Por D. Vicente Rodriguez de Arellano y El ArCO${ }^{19}$; las comedias de corte popular de Gaspar Zavala y Zamora El día de campo, que editamos en otro lugar ${ }^{20}$, y Las

15. Cf. CAÑas Murillo, Jesús. "Una "escena unipersonal” entre dos siglos: El Entretenido, ó La brevedad sin sustancia, de Manuel González”, citada.

16. Impresa "En Cadiz, por D. Manuel Ximenez Carreño, Calle Ancha, Año de 1790". De esta obra de Iriarte hay edición moderna incluida en el volumen de su Teatro original completo, preparado por Russell P. Sebold, y publicado en Madrid: Cátedra (Letras Hispánicas, 654), 2010 (el tomo contiene Hacer que hacemos, El señorito mimado, La señorita malcriada, El don de gentes o La habanera, Donde menos se piensa salta la liebre, La librería, Guzmán el Bueno; esta última figura entre las páginas 689 y 708). Anteriormente había visto la luz una edición facsímil de la versión aparecida en Cádiz, que acabamos de citar, publicada en Algeciras: Instituto de Estudios Campogibraltareños, 1999.

17. Valencia: José Ferrer de Orga, 1813.

18. Publicado en Madrid, en la Imprenta Real, en 1794, con la aclaración de que se trata de una "Scena trágica", y de que fue "Representada por la señora Catalina Fabiani Munteis en el coliseo de la Cruz en el mes de febrero de este año de 1794", y "Escrita por Fermín del Rey, primer apuntador de la Compañía de Manuel Martínez». Para esta obra compuso, en 1794, Fermín del Rey una "Introducción a la scena trágica intitulada Policena», que se conserva, en manuscrito, en la Biblioteca Municipal de Madrid (sig. 1-158-26), y que recibió censura de Santos Díez González, firmada el 24 de enero de 1794. Cf. Aguilar Piñal, Francisco. "REY (FERMIN DEL). Apuntador de teatro». En su obra Bibliografía de Autores Españoles del Siglo XVIII, VII (R-S). Madrid: CSIC, 1993, pp. 85-91. Ver, también, HERRERA NAVARRO, Jerónimo. "REY, FERMIN DEL (?-?)». En su libro Catálogo de autores teatrales del siglo XVIII. Madrid: Fundación Universitaria Española, 1993, pp. 376-378; McClelland, I. L. Spanish Drama of Pathos 1750-1808. Volume II: Low Tragedy. Liverpool: Liverpool University Press, 1970, pp. 388-389 (este volumen, junto al primero, titulado High Tragedy, fue traducido y publicado en 1998, en Liverpool University Press, con el título Pathos dramático en el teatro español de 1750-1808, 2 vols.; vol. I. La alta tragedia; vol. II. La tragedia menor); y SuBIRÁ, José. "Un "melólogo" curioso y una "introducción" a otro melólogo: La escena trágica "Policena” ". Revista de la Biblioteca, Archivo y Museo del Ayuntamiento de Madrid, año V, octubre de 1928, n. ${ }^{\circ}$ XX, pp. 360-364.

19. Valencia: En la Imprenta de Estévan, Año 1818.

20. Cf. Cañas Murillo, Jesús. "Teatro de mayorías para deleite de minorías: El día de campo, de Gaspar Zavala y Zamora». En Cañas Murillo, Jesús; Grande Quejigo, Francisco Javier y Roso Díaz, José (eds.). Literatura Popular e Identidad Cultural. Estudios sobre Folclore, Literatura y Cultura Populares en el mundo occidental. Cáceres: Universidad de Extremadura, 2010, pp. 235-257. Sobre esta obra, ver, también, en este mismo volumen que acabamos de citar, el trabajo de Álvarez Franco, Malén. "El día de campo en el teatro popular de la Ilustración: Gaspar Zavala y Zamora», en pp. 229-234. 
tramas de Garulla, pieza en un acto ${ }^{21}$. La elaboración de obras de esta índole se mantuvo viva también en el siglo XIX. De hecho, incluso a finales de esta centuria se ofrecen a los espectadores piezas similares. Es el caso, por ejemplo, de Padre e bijo. Comedia en un acto traducida del francés, impresa sin identificar a su autor $^{22}$; o de Un deudor de viaje ó Don Robreño hecho comico. Fin de fiesta, escrita por Eduardo Sala y Sauri, estudiada y editada por mí en otro lugar²3.

En este grupo igualmente se incluye el Diálogo trágico. Intitulado La Raquel. Facil de egecutar en casas particulares. Sacado de la bistoria y adornado con intervalos de música. Por un aficionado, del que aquí nos ocupamos.

\section{El AUTOR Del DiÁlOGO tRáGICO INTTTULADO LA RAQUEL Y SU OBRA}

El creador de La Raquel no es identificado en la portada del texto que manejamos, que no es sino el publicado en Valencia, por José Ferrer de Orga, en el año 1813. El título de la obra se refiere a él como «un aficionado», como antes hemos podido comprobar: Diálogo trágico. Intitulado La Raquel. Facil de egecutar en casas particulares. Sacado de la bistoria y adornado con intervalos de música. Por un aficionado. Jerónimo Herrera Navarro ${ }^{24}$ incluye la pieza entre las composiciones del escritor José March y Borrás, natural de Castellón, y fallecido, según recoge Francisco Aguilar Piñal, en $1796^{25}$. De él se conserva otra obra, también impresa como anónima, pero atribuida a él por Justo Pastor Fuster, como explica el mencionado Aguilar Piñal, titulada La Rani-Ratiguerra, Poema jocoso, dedicado a Juan Rana, y dado a luz por uno de sus más afectos alumnos, publicado en Valencia, por Francisco Burguete, en 1790.

Herrera Navarro, basándose en Justo Pastor Fuster y en Juan Antonio Balbás ${ }^{26}$, incluye La Raquel entre las obras de March y Borrás, al igual que el «Drama original" Ilphis y Zulia. Sobre la biografía de este autor, informa que nació en

21. Valencia: Por Ildefonso Mompié, 1822. Sobre otras obras dramáticas sobre el mismo tema, véase Álvarez Franco, Malén. «Guzmán el Bueno, un héroe medieval en una tragedia neoclásica española». En CAÑAs Murillo, Jesús; Grande QuejIgo, Francisco Javier y Roso Díaz, José (eds.). Medievalismo en Extremadura. Estudios sobre Literatura y Cultura Hispánicas de la Edad Media. Cáceres: Universidad de Extremadura, 2009, 660+XVIII pp., pp. 555-562.

22. Madrid: Imprenta de D. José María Repullés, 1837.

23. Cañas Murillo, Jesús. "Un fin de fiesta del siglo XIX: Un deudor de viaje ó Don Robreño becho comico, de Eduardo Sala y Sauri». Cuadernos de Ilustración y Romanticismo. Revista del Grupo de Estudios del Siglo XVIII, 2007, n. ${ }^{\circ}$ 15, pp. 239-270, también recogido en su libro Cajón de sastre, cit., pp. 459-489.

24. Herrera NAVArRo, Jerónimo. "March y Borrás, José (?-1796)». En Catálogo de Autores Teatrales del Siglo XVIII. Madrid. Fundación Universitaria Española, 1993, p. 285.

25. Aguilar Piñal, Francisco. "March y Borrás (José)». En su Bibliografía de Autores Españoles del siglo XVIII, V, L-M. Madrid: CSIC, 1989, p. 399.

26. PASTOR Fuster, Justo. Biblioteca Valenciana de los Escritores que florecieron hasta nuestros dias. Con adiciones y enmiendas a la de D. Vicente Ximeno. Valencia: 1827-1830, 2 vols. (sobre March 
Castellón, «de familia noble», que falleció en Valencia, donde se afincó desde época temprana de su vida, "el día 3 de junio de 1796", y que estuvo dedicado a la poesía. Fuster previamente había aportado, junto a esas, otras noticias. Explicó que era poseedor de una extensa biblioteca, que impulsó la publicación de la obra Trobas de Mosen Jaime Febrer, y que su muerte se produjo, en la fecha antes mencionada, en la Parroquia de San Nicolás. Fuster le atribuye la composición de múltiples poemas, que dejó manuscritos e impresos, entre los cuales dice conocer, aparte de la Rani-Ratiguerra, ya citada, los siguientes: Versos á los terremotos de Orán en 1793, dirigidos al Conde de Noroña; Sátira intitulada la Opinion; El drama de Ilphis y Zulia, original; Cicides y Pagres, poema en prosa traducido del francés; Heroida de Mr. Duch á la muerte de Decio en el campo de batalla, traducción del alemán; La mujer, poema traducido del francés; Cantos de una amazona, por Mr. Weisse, traducción del alemán; una Egloga a la muerte de la Duquesa de Frias; la Tragedia titulada la Raquel; y «finalmente una disertación sobre la literatura española». Son datos que, prácticamente en su literalidad ${ }^{27}$, reproduce Balbás en sus Castellonenses Ilustres ${ }^{28}$.

Centrémonos en su obra Diálogo trágico. Intitulado La Raquel. Facil de egecutar en casas particulares. Sacado de la historia y adornado con intervalos de música. Por un aficionado, de la que nos ocupamos en este trabajo.

La Raquel aborda el tema de los amores de la Judía de Toledo con el Rey Alfonso VIII de Castilla, como antes hemos explicado. Se trata de un drama trágico, de pocos personajes, pues solo se incluyen dos, Raquel y Alfonso VIII, fácil, pues, de representar en casas particulares y, por ello, de montaje no excesivamente costoso, que relata las angustias y dudas que sufre la amante de Alfonso VIII debido al papel que ocupa en la corte, y a su actuación como gobernante del reino por decisión, y delegación, del monarca propietario del trono en esos momentos, y debido a los malos presagios que la asaltan; y las angustias y dudas que sufre el propio soberano, igualmente asaltado por malos presagios que le producen una gran agonía vital.

La acción recoge los últimos momentos de la vida de Raquel, los instantes previos a su muerte a manos de los sublevados contra ella, y los propios instantes de su asesinato y de su muerte en brazos de Alfonso que acudía, lleno de sensaciones negativas que le producen angustia, a encontrarse con ella. Tiene dos partes paralelas, seguidas de un final trágico. En la primera hallamos un largo parlamento de Raquel, en el que la heroína manifiesta a los espectadores los temores que la asaltan y que no se puede explicar racionalmente, y el consiguiente sufrimiento

\footnotetext{
y Borrás, tomo II, p. 171). BAlBÁs CruZ, Juan Antonio. Castellonenses Ilustres. Apuntes biográficos. Castellón de la Plana: Tipografía de José Armengot, 1883 (sobre March y Borrás, pp. 108-110).

27. Se detectan abundantes coincidencias de redacción, que muestran un transvase directo desde la obra más temprana, la de Fuster (1830), a la posterior, la de Balbás (1883).

28. Balbás CruZ, Juan Antonio. "D. José March y Borrás». En su libro Castellonenses Ilustres, citado, pp. 108-110.
} 
que padece, mientras se dirige al Salón del Trono a ocuparse de asuntos de gobierno por delegación del Rey. En la segunda se inserta un largo parlamento de Alfonso VIII -pronunciado mientras se dirige al encuentro de su amante judía-, en el que manifiesta los malos presentimientos que lo acosan y le producen dudas, terrores y sobresaltos que lo sobrecogen, sin que sepa exactamente la causa. El atentado contra Raquel, que supone el fin, aunque no inmediato, de su vida, y el encuentro de ella con su amante, con quien dialoga antes de morir, y la despedida de los enamorados ponen colofón al argumento.

La Raquel se incluye en el género dramático que conocemos como tragedia neoclásica española ${ }^{29}$. Es una obra breve. Pero, por el tipo de composición que se ha hecho de ella, es una auténtica tragedia neoclásica, completamente respetuosa con la normativa clasicista defendida por los preceptistas y los literatos reformistas de la Ilustración. Mantiene escrupulosamente las unidades, pues transcurre toda ella en el Salón Regio de Palacio, en la estancia previa al lugar donde se halla situado el trono; se cuenta una historia única, la muerte de Raquel, sin que se incluyan segundas acciones o historias secundarias; se desarrolla en muy pocas horas, en los instantes previos a la rebelión de los castellanos que ponen fin a la vida de la hermosa Judía, por lo que el tiempo del argumento coincide, podemos afirmar que exactamente, con el tiempo en que tiene lugar la representación, el montaje de la obra. La escasa extensión del texto, que consta tan solo de trescientos diecinueve versos, favorece el respeto absoluto de la norma de las unidades. En la pieza se incluyen pocos personajes, únicamente dos, Alfonso VIII y Raquel. Se plantean reducidos temas, pues dos son los que se abordan, el amor y la muerte, aunque asuntos políticos sean mencionados pero sin hacer gran hincapié en ellos, dejándolos implícitos, pues se trataba de un asunto que gozaba de fama previa y

29. Sobre la tragedia neoclásica española, vid. los trabajos de CAÑAs MuRILlo, Jesús. «Tipología de los personajes en las tragedias de Vicente García de la Huerta». En Simposio Internacional «Vicente García de la Huerta» (1787-1987). CAÑas Murillo, Jesús y LAma, Miguel Ángel (eds.). Revista de Estudios Extremeños. Badajoz: Servicio de Publicaciones de la Excma. Diputación Provincial, mayo-agosto de 1988, XLIV, II, pp. 349-377; "Sobre la poética de la tragedia neoclásica española». Revista de Filología y Lingüística de la Universidad de Costa Rica, enero-junio 1999, XXV, 1, pp. 115-131; "Raquel, de Vicente García de la Huerta, en la tragedia neoclásica española». Anuario de Estudios Filológicos, 2000, XXIII, pp. 9-36; "García de la Huerta y la tragedia neoclásica». En HuERTA CALVO, Javier (dir.). Historia del teatro español. Madrid: Gredos, 2003, 2 vols., vol. II. Doménech Rico, Fernando y Peral VeGa, Emilio (coords.). Del Siglo XVIII a la época actual, pp. 1577-1602; Romero FERRER, Alberto y ÁlvarEZ BARRIENTOS, Joaquín (coord.). "La tragedia neoclásica española». En Literatura Española en los siglos XVIII $y$ XIX, publicado en internet, Liceus, El portal de las Humanidades, www.liceus.com/cgi-bin/aco/ lit/01/0112.asp\#xviii, 2003; "El poderoso como personaje y como tema en la tragedia neoclásica española». Cuadernos de Ilustración y Romanticismo. Revista Digital del Grupo de Estudios del Siglo XVIII, 19, Teatro ilustrado y modernidad escénica, 2013, pp. 85-109 (http://revistas.uca.es/index.php/cir/article/ view/1835); "El tema de la monarquía entre la comedia nueva y la tragedia neoclásica española: la Ilustración frente al Barroco». Annali. Sezione Romanza. Nápoles: Universidad de Nápoles L'Orientale (Italia), L'Orientale Editrice, 2014, LVI, 1, pp. 97-126; La tragedia neoclásica española. Madrid: Ediciones Liceus (Aprendizaje Express, 1), 2017. 
era ya conocido por buena parte de los espectadores, dado el éxito que había antes cosechado su predecesora, Raquel, de Vicente García de la Huerta, que había difundido la leyenda y le había dado un enfoque dramático que ya le era familiar al auditorio, o a una parte importante de él.

La creación dramática que seguramente inspiró al autor del Diálogo trágico intitulado La Raquel no fue otra sino la tragedia Raquel de Vicente García de la Huerta, que acabamos de mencionar. Los hechos incluidos en aquella se muestran muy ligados a los que figuran en el argumento de la composición salida de la pluma del zafrense y podían ser conocidos por los posibles receptores del Diálogo. Hallamos, igualmente, concomitancias en los temas, así como en las alusiones a problemas políticos y de gobierno, a la mala praxis de Raquel como cabeza del reino por delegación regia. Encontramos, también, concomitancias en la construcción y tratamiento de los personajes, Alfonso y Raquel, ambos construidos sobre el tipo del héroe trágico ${ }^{30}$, ambos meditativos, que sufren por sus pasiones y sus contradicciones, angustiados, agónicos en el sentido unamuniano, con torturas interiores que coinciden con las padecidas por los protagonistas de la obra de García de la Huerta. Incluso en ocasiones detectamos similitudes con el lenguaje y con expresiones que utilizan los protagonistas de ambas piezas, la tragedia larga del extremeño y la tragedia breve que nos ocupa. Así, en boca de Raquel se pone la siguiente expresión en el texto del castellonense: "Amar, y ser amada es mi delito", o [me matan] "Por amarte», que nos trae inmediatamente el recuerdo de otra anterior inserta, en contexto similar, en Raquel: «Tu amor es mi delito / la plebe quien le juzga y le condena ${ }^{31}$.

Del Diálogo trágico. Intitulado La Raquel, a día de hoy, nada sabemos sobre su fecha exacta de composición. Ni hemos conservado, hasta ahora, datos sobre posibles montajes. No obstante, quizá debió de recibirlos, y obtener, en ellos, buena aceptación, dado que no está carente de notable calidad. El hecho de que conservemos de él tres ediciones, hechas dos de ellas en el mismo año de publicación, 1813, en Valencia, y en la misma Imprenta de José Ferrer de Orga, puede ser un buen indicio de ello. Sobre todo, en el caso de estas dos últimas versiones valencianas, pues pueden indicar que los ejemplares de la primera en aparecer se agotaron con prontitud -lo cual presupone un interés de los receptores por leer su texto, tal vez tras haberlo presenciado en algún montaje ( $\vdots \mathrm{O}$ algunos montajes?) privado o público-; y ello llevó al editor a realizar una nueva impresión para satisfacer con ella la curiosidad, y demanda, de los lectores del momento y, evidentemente, obtener, así, más beneficios económicos.

30. Cf. Cañas Murillo, Jesús. "Tipología de los personajes en las tragedias de Vicente García de la Huerta", citado.

31. García De la HuerTa, Vicente. Raquel. Ed. Jesús Cañas Murillo. Madrid: Bolchiro S. L., 2014, vv. 2223-2224, p. 190. 
De La Raquel, como acabamos de indicar, conocemos dos impresiones, en suelta, editadas en el mismo año, en la misma imprenta y en la misma ciudad: Valencia, José Ferrer de Orga, 1813; y una tercera, igualmente en suelta, en la que no figura fecha alguna de impresión, efectuada en Salamanca, en la Imprenta de Francisco Tóxar. No sabemos el orden de su aparición pública. Pero entre las dos primeras, las valencianas, existen variantes ortográficas importantes, siendo, en una de ellas, la que utilizamos como base para nuestro estudio y para la edición que más adelante incluimos, la acentuación más moderna -en relación con la ortografía imperante en momentos posteriores de la historia- que la otra, más acorde con usos de anteriores épocas de la Ilustración. En la portada de la primera -que más adelante reproducimos-, a la que nos referimos, leemos lo siguiente: "Diálogo trágico. / Intitulado: / La Raquel. / Fácil de egecutar en casas / particulares. / Sacado de la historia, / y adornada con intervalos de música. / Por un aficionado. / Valencia: / Por Jose Ferrer de Orga. / Año 1813. / Se hallará en la Librería de José Carlos Navarro, calle de la Lonja de la Seda: / asimismo un gran surtido de Comedias antiguas y modernas, / Tragedias, Autos Sacramentales, Sainetes y Unipersonales». En la segunda, igualmente reproducida después: "Diálogo trágico. / Titulado: La Raquel. / Fácil de executar en casas / particulares. Sacado de la historia / y adornado con intervalos de musica. / Por un aficionado. / En Valencia / Por José Ferrer de Orga. / Año 1813. / Se hallará en la Librería de José Carlos Navarro, Calle de la Lonja de la Seda: / asi mismo un gran surtido de Comedias antiguas y modernas, Tragedias, / Autos Sacramentales, Saynetes y Unipersonales». En la lectura de ambas portadas, como vemos, podemos detectar las variantes ortográficas a las que nos hemos referido, y alguna textual: «Intitulado" frente a "Titulado"; "egecutar" frente a "executar"; "adornada" frente a "adornado"; "música" frente a "musica»; "Valencia» frente a "En Valencia»; "Jose» frente a "José»; "asimismo» frente a "asi mismo»; "calle» frente a "Calle»; "Sainetes» frente a «Saynetes». Idéntica situación hallamos en el interior de ambas sueltas. ¿Puede ser la edición de acentuación más moderna la más reciente de las dos, y fruto de una corrección posterior de la más arcaizante? Tal vez.

En la suelta salmantina mencionada, la versión del título de la obra que leemos es la siguiente: Diálogo trágico titulado La Raquel: facil de executar en casas particulares, sacado de la historia y adornada con intervalos de música por un aficionado. Fue realizada en Salamanca, por la Imprenta de D. Francisco Tóxar, sin que se informe del año de edición. No sabemos, pues, si es anterior o posterior a las impresiones valencianas. Francisco de Tóxar pudo vivir entre 1786 y 1799, y trabajaría, quizá, en Salamanca en su oficio entre 1786 y 1799, o los primeros años del siglo XIX, por lo que, en este caso, la suelta sería anterior a esta última fecha. En la ficha del ejemplar de esta que se conserva en la Universidad Complutense de Madrid (signatura CT 82-2SAI,4), se indica que pudo ser impreso hacia 1800. En la ficha del ejemplar de la British Library, se sitúa su aparición pública en los alrededores de 1780 . En ambos casos no se incluyen mayores precisiones, ni se explican los fundamentos de tales dataciones. Si fuesen correctas estas suposiciones, 
de todas las ediciones conservadas, y localizadas, del Diálogo trágico intitulado La Raquel, la suelta de Salamanca sería, cronológicamente, la primera en ver la luz.

De la impresión salmantina hemos localizado ejemplares en la British Library, en la Biblioteca Pública del Estado sita en Castellón de la Plana, y en los fondos bibliográficos pertenecientes a la Universidad Complutense de Madrid (signatura CT 82-2SAI,4). De las impresiones valencianas hay catalogados ejemplares de la anunciada como Diálogo trágico intitulado La Raquel en la Biblioteca de Cataluña (signaturas 83-8-C 58/3; y 16-III-16/1). De la anunciada como Diálogo trágico titulado La Raquel, en la Biblioteca de Cataluña (signatura 834.6TSai 8. ${ }^{\circ}$ ) y en la Universidad de Navarra (signatura FA.Foll 005.456).

De los impresores de las sueltas conservadas de La Raquel conocemos ciertos datos biográficos y curriculares. Francisco de Tóxar nació en Granada, según Francisco Aguilar Piñal ${ }^{32}$. Se afincó en Salamanca, donde ejerció una fecunda actividad profesional durante bastantes años (probablemente entre 1786-1799, según se repite; aunque, posiblemente, el periodo de tiempo sea mayor, pues hay obras impresas en su Oficina fechadas a principios del siglo XIX, en 1802, en 1804, en 1805, en $1807 . .$.$) . Casó con una hermana del poeta dieciochesco, de la llamada$ escuela salmantina, José Iglesias de la Casa, de cuyas Poesías póstumas ${ }^{33}$ se encargó de la impresión, pues aparecieron en su taller, en 1798, en dos volúmenes, con un "Prólogo" (tomo I, pp. IX-XII), una "Advertencia de los Editores» (tomo I, pp. XIII-XV) y una "Advertencia para este segundo tomo» (tomo II, pp. VII-XIV), redactados por él. Era de pensamiento reformista, liberal, ilustrado, por lo que tuvo que enfrentarse a problemas con la Inquisición del momento. Fue traductor (así, de la Colección de cuentos morales de Jean-François de Saint-Lambert, impresa por él en 1796), editor de novelas y obras teatrales, y escritor ocasional. A él se atribuye La Filósofa por amor o Cartas de dos amantes apasionados y virtuosos (Salamanca, $1799)^{34}$, que, en realidad, no es sino una refundición de un texto del francés Restif de la Bretonne. Y es autor de la Comedia nueva intitulada: El bastardo de Suecia. Sin mugeres. En tres actos. Por Francisco de Toxar, impresa en Alcalá, por Isidro López, en $1792^{35}$. También fueron producto de su imprenta algunas publicaciones periódicas por algún tiempo, como el Semanario de Salamanca, que imprimió durante un año, y algunas ediciones de textos conmemorativos y de circunstancias, como la Oración Fúnebre que a la buena memoria del Ilustrísimo Señor D. Antonio Gaona, Obispo Prior de la Real Casa de Santiago de Uclés, dixo en la Capilla de San Gerónimo de la Universidad de Salamanca el día 28 de julio de

32. Aguilar Piñal, Francisco. "Tojar (Francisco de)». En Bibliografía de Autores Españoles del siglo XVIII, VIII, T-Z. Madrid: CSIC, 1995, pp. 60-61.

33. De Toxar, Francisco. Poesías póstumas de D. Josef Iglesias de la Casa, Presbítero. Salamanca, Año MDCCXCVIII, 2 tomos.

34. Cf. De TÓJAR, Francisco. La Filósofa por amor o Cartas de dos amantes apasionados y virtuosos. Edición de Joaquín Álvarez Barrientos. Cádiz: Universidad de Cádiz, 1995.

35. Aguilar Piñal. "Tojar (Francisco de)», citado, p. 60. 
1804. El M. D. Miguel Martel, del gremio y claustro, Catedrático de Filosofía Moral en la misma Universidad (Salamanca: En la Oficina de D. Francisco Tóxar, 1804, 35 pp.).

José Ferrer de Orga se encargó de la impresión de las dos sueltas valencianas conocidas de La Raquel. De familia de impresores, fue hijo de Antonia de Orga y Gómez -a su vez hija del conocido impresor José de Orga- y del tipógrafo Mariano Ferrer. Terminó su vida completamente ciego, debido a las cataratas que padeció, que fueron operadas, por lo que recuperó durante un tiempo la visión, pero reproducidas más adelante sin posibilidad de remedio. Debido a ello, su esposa, primero, hubo de relevarlo en la dirección del negocio familiar, ayudada por su primo José de Orga y Piñana, y, después, el mayor de sus vástagos, José Ferrer y Viñerta, a quien ayudó en estas tareas su cuarto hermano, Andrés. Tuvo siete hijos, uno de ellos fallecido a edad temprana. Aprendió su oficio, como cajista, revisor de pruebas y ajustador de los moldes, con su tío José de Orga. Falleció en Valencia, el día 9 de mayo de 1849. A su muerte su negocio pasó a manos de su hijo Andrés, dado que el mayor, José, se trasladó a Madrid a ejercer su oficio. Los trabajos salidos de la que había sido su imprenta aparecieron con la marca Ferrer de Orga, pero sin que ya apareciese en ella el nombre de José. Sus trabajos se caracterizan "por su limpieza, hermosura y corrección", como bien indica José Enrique Serrano y Morales ${ }^{36}$, y esa pulcritud la mantuvo también la Imprenta Ferrer de Orga, que, a su muerte, mantuvo en funcionamiento el negocio familiar, ofreciendo al público obras tan reputadas y apreciadas, incluso hoy en día, como el Catálogo de la biblioteca de Salvá, escrito por D. Pedro Salvá y Mallen, y enriquecido con la descripción de otras muchas obras, de sus ediciones, etc. (Valencia: Imprenta de Ferrer de Orga, á espaldas del Teatro Principal, 1872, 2 tomos).

\section{UNA NUEVA EDICIÓN DE LA RAQUEL}

En la última parte del presente trabajo vamos a ofrecer la primera edición moderna, no digitalizada a partir de una versión de época, que se realiza de la obra de José March y Borrás, impresa en su momento sin desvelar el nombre de su autor, Diálogo trágico. Intitulado La Raquel. Facil de egecutar en casas particulares. Sacado de la historia y adornado con intervalos de música. Por un aficionado. Nuestra versión se va a basar en un ejemplar de una de las dos ediciones publicadas en Valencia, en la oficina de José Ferrer de Orga, en el año 1813, aquella que parece presentar unos usos ortográficos más próximos a los que se emplearon

36. SERRANO y MORALES, José Enrique. «Ferrer de Orga-José». En su Reseña histórica en forma de Diccionario de las Imprentas que han existido en Valencia desde la introducción del arte tipográfico en España hasta el año 1868. Estudio introductorio de Nicolás Bas Martín. Valencia: Ayuntamiento de Valencia, 2000, pp. 164-176. La cita en p. 169. 
con posteridad a la fecha de su publicación. Ya antes nos referimos a este asunto y lo explicamos con mayor detenimiento. Es una edición limpia y cuidada, aunque con algunas erratas - no excesivas- evidentes, quizá fruto de la rapidez con que fue impresa, tal vez para aprovechar la demanda de la obra por parte de curiosos lectores del momento; aunque, pese a ello, no deja de ser muestra de la calidad del trabajo de su impresor, y del cuidado que se ponía en el taller de este en la corrección de pruebas. Utilizaremos como base de nuestra labor el ejemplar que pertenece a nuestra propia biblioteca particular, que incluye toda la obra en un pliego repartido en ocho páginas, que se halla en un excelente estado de conservación, y que ha llegado a nuestros días sin manchas de ningún tipo, con el papel casi nuevo y sin desbarbar.

El ejemplar de mi biblioteca es una suelta de principios del siglo XIX, de 1813, como vimos. En ella, al igual que en el resto de los ejemplares que hemos consultado, y que hemos mencionado en páginas anteriores, se reserva la primera página para incluir la portada. A partir de la segunda, figura el texto, sistemáticamente distribuido en dos columnas, del Diálogo trágico. Intitulado La Raquel.

La edición que hemos realizado de La Raquel tiene carácter paleográfico. En ella hemos respetado la grafía y puntuación que encontramos en el original que hemos tomado como base, la versión incluida en la impresión de José Ferrer de Orga, del año 1813, que antes hemos identificado, la versión en la que la pieza es denominada Diálogo trágico. Intitulado La Raquel. Facil de egecutar en casas particulares. Sacado de la historia y adornada con intervalos de música. Por un aficionado. Y no aquella en la que leemos: Diálogo trágico. Titulado: La Raquel. Fácil de executar en casas particulares. Sacado de la historia y adornado con intervalos de musica. Por un aficionado. Al final de nuestro trabajo reproducimos ambas portadas para que sirvan de ilustración a nuestras anteriores explicaciones. Nuestra edición ha sido respetuosa con las grafías de la suelta que le sirve de base, aunque se hayan corregido las erratas detectadas, explicándolo en las correspondientes notas. Con ella hemos pretendido facilitar el conocimiento y estudio de los usos ortográficos propios del siglo XVIII español. Hemos numerado los versos que aparecen en la obra, en contra del criterio utilizado en la suelta que nos sirve de punto de partida, y hemos añadido la información sobre la parte del texto que se incluye en cada una de las páginas de que consta nuestra impresión base.

Con este trabajo hemos pretendido dar a conocer parcelas poco accesibles para el lector actual de la literatura española del siglo XVIII, facilitar el acercamiento a textos poco difundidos, que han permanecido ocultos por la acción del paso de los tiempos, pero que no por ello carecen de interés. Con ello deseamos contribuir a rescatar una parte importante de patrimonio bibliográfico español, que hasta ahora permanece en la sombra, y completar, de tal modo, el panorama habitualmente presentado de la cultura y la literatura españolas de la era de la Ilustración. 


\title{
5. DiÁLOGO TRÁGICO INTITULADO LA RAQUEL: LA EDICIÓN
}

\author{
[1] DIÁlOGO TRÁGICO. \\ INTITULADO: \\ LA RAQUEL. \\ FÁCIL DE EGECUTAR EN CASAS \\ PARTICULARES. \\ SACADO DE LA HISTORIA, \\ Y ADORNADO ${ }^{37}$ CON INTERVALOS DE MÚSICA. \\ POR UN AFICIONADO.
}

\author{
VALENCIA \\ POR JOSÉ FERRER DE ORGA \\ AÑO 1813.
}

Se hallará en la Librería de José Carlos Navarro, calle de la Lonja de la Seda: asimismo un gran surtido de Comedias antiguas y modernas, Tragedias,

Autos Sacramentales, Sainetes y Unipersonales.

\section{${ }^{[2]}$ PERSONAS.}

Raquel.

Alfonso VIII

Salon Regio de Palacio con puertas grandiosas á el foro, las cuales se abrirán á su tiempo, y descubrirán trono en su interior; mesa magnífica con relox en ella, y junto á ella una silla en la que estará sentada Raquel apoyada sobre el brazo izquierdo, y el derecho le tendrá caido con el pañuelo en el suelo; antes de tirarse el telon precederá un fuerte estrépito que descenderá por grados á un piano armonioso de fagotes y clarines obligados que durará hasta que vuelve sobre sí asustada y despavorida, en seguida andará por el teatro del mismo modo, y la música espresará igualmente sus afectos. Despues de tranquilizada dice.

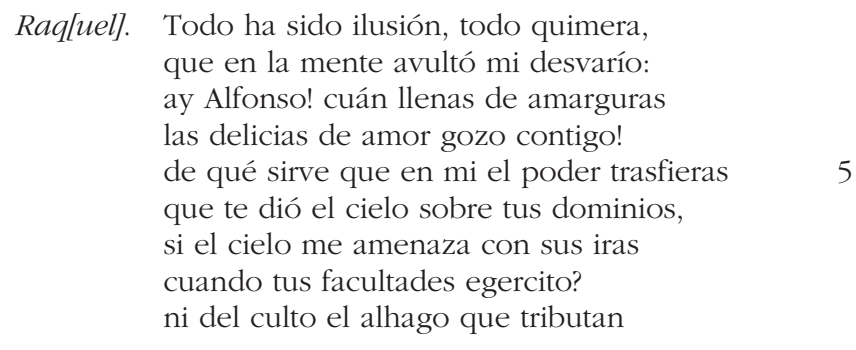

37. En la impresión que utilizamos como base para nuestra edición, adornada, lectura que crea anacoluto, por lo que adoptamos la versión incluida en la otra edición valenciana que conocemos, y en la editada en Salamanca, por Francisco de Tóxar, s. f., a las que anteriormente nos hemos referido. 
lisonja, y sumision al poderío;

ni el humo del incienso que á mis aras

el servil cortesano ofrece fino;

ni el cúmulo agradable de preseas,

de galas suntuosas, y atavíos

que á competencia prodigos ofrecen

á mi adorno Zeilan, Oriente, y Tiro;

ni el ser de Alfonso amada con estremo,

ni el mirarle sujeto á mi alvedrío,

ni la posesion de siete años,

ni la seguridad de su cariño,

bastan á disipar el sobresalto,

el horror, y el afan que ha introducido

en mi turbado pecho un fatal sueño,

sueño espantoso! sueño el mas impío

déjame en paz, no turbes mi reposo!

huye, huye::- mas cómo? cuándo avivo

con mi amor los efectos que le causan?

Amar, y ser amada es mi delito.

Cielos, sin destrozar mi amant[e] pecho

${ }^{[3]}$ de él no puedo arrancar al dueño mio;

amor por conservar en él su imagen

rasgos de fuego vió, para esculpirlo.

Se queda suspensa, y la música sigue la meditacion que debe tener por un rato.

Arrancarle del pecho? separarle?

sin Alfonso Raquel? qué es lo que digo?

primero que en mi pecho Alfonso falte

venas de fuego correrán los rios;

producirá la nieve los volcanes,

la tierra ocupará del sol el sitio;

los cielos pararán; el aire torpe,

del modo de alentar perderá tino,

40

dispondrá de los seres la gran masa

que su reproducion pase al olvido;

todo puede mudarse, todo, todo,

menos la fe que por Alfonso animo ${ }^{38}$.

Corto espacio de música, en que Raquel mira si viene Alfonso.

Pero no viene Alfonso, su tardanza

causa en mi corazon nuevos martirios:

conturbado mi espíritu no encuentra

las voces del dolor para sentirlo,

pues torpes con los ayes de la queja

38. En el ejemplar que manejamos, animó, por errata que no se halla en otras impresiones. 
del formidable trueno, que los velos rasgó de la mansion del Juez divino: de cuya mano vi caer la sentencia que impulsó su justicia á mis delitos. Qué horror! qué turbacion! qué arredramiento! discurso atribulado, busca arbitrios para olvidar recuerdos que tan solo sirven de dar aumento::- mis deliquios en estos pavimentos me presentan de nuevo la sentencia:: alli la miro:: caractéres infinitos! líneas tristes! á vuestro rigor cedo, ya desisto de amar á Alfonso, ya su amor renuncio. Andante triste.

Pero ay! que para hacerlo falta el brio! ${ }^{[4]}$ un pavor se derrama de mis venas, que entorpece el discurso, y los sentidos::yo no sé donde estoy, ni que me pasa::Ay Alfonso! Ay mi bien! que te he perdido.

Se recuesta en la silla, y la música manifestará su consternación, subsistirá unos cortos instantes en esta situación, despues se levantará, en aptitud ${ }^{39}$ de estar meditando, y seguirá diciendo.

39. Así en las dos ediciones de 1813 publicadas por José Ferrer de Orga. Podría tomarse como errata, por actitud, pero la lectura aptitud es aceptable, en ese contexto, según la definición que de 
Asi como la idea algunas veces nos finge sueños de placer nacidos, y de glorias mentidas llena el pecho, haciendo rico al pobre, grande el chico, y después de borradas ${ }^{40}$ las especies reconoce que todo fue fingido. Tu decreto fatal, tu desventura no puede ser Raquel tambien lo mismo? quien lo duda: por otra parte no hallo quien se atreva á cumplir el vaticinio. Los vasallos adoran en Alfonso, su corazon respetan en el mio; y saben, que de un Rey tan solamente puede juzgar el arbitro divino. La reina al disimulo y la paciencia hace de sus pesares sacrificio, y no creo que emprehenda cosa alguna que pueda disgustar á su marido. Estando como estoy asegurada, obsequiada de todos sus dominios, respetada del noble y del plebeyo, árbitra del poder, y el beneficio, y últimamente viéndome señora del corazon del Rey, por qué me aflijo? por qué temo? por qué distraigo á Alfonso? por mi amor al vasallo echa en olvido, en los cargos no atiendo al castellano, al hebreo el favor tan solo aplico: pero aunque sea así, se opone Alfonso? al reves, lo autoriza su cariño, y si la magestad condena el yerro, absuelve el yerro amor::-

Se serena de pronto, y á un golpe de música de terror se sobresalta de nuevo.

:: Pero el cuchillo sangriento de la culpa que mi pecho sin cesar hiere; de mi atroz delito el peso enorme, que mi frente abruma, ha cubierto mis dias de conflictos. Si veré yo otra Cava ${ }^{41}$ que la España vuelva á inundar de males, y castigos?

esa palabra recoge el Diccionario de Autoridades de la RAE: "APTITUD. J. f. Buena disposición para obrar, habilidád y facilidád y modo para hacer alguna cosa».

40. En el ejemplar que manejamos, deborradas, por errata.

41. En el ejemplar que manejamos, cava. 
LAS OTRAS RAQUEL: EL DIÁLOGO TRÁGICO DE JOSÉ MARCH Y BORRÁS

Españoles, aunque en mít $^{42}$ reina el odio que profesa al cristiano el circunsciso, nada temas: Raquel, no tiene padre que traiga á España Moros vengativos, que renueven las míseras desgracias ${ }^{[5]}$ que tan infausto hicieron á Rodrigo. Mas la hora se acerca en que es forzoso hacer obstentacion del poderío.

Qué vano! qué orgulloso! qué altanero con el mando se pone un genio altivo! Cómo en su pecho se difunde el gozo cuando á sus plantas mendigar sumiso ve el furor, ó la gracia el pretendiente! nada puede perturbar tu regocijo Raquel...

...las ilusiones son efecto del sueño... darlas crédito delirio.

Pequeña pausa en la que el relox da las doce. Pero las doce dan, y Alfonso tarda, mas cuándo Alfonso tan temprano vino? dejadme en paz ideas...

Abren las puertas, $y$ se ven varios con memoriales. ...Ya las puertas

que dan al real salon abiertas miro, y esperándome ${ }^{43}$ están cuantos desean conseguir de mi mano beneficios.

Presentarme es forzoso; en cada paso que doy hacia el salon un monte animo, y al llegar á sus puertas vuelve el alma á sentir el temor del vaticinio infausto de su muerte, qué rezelo? qué dudo? cuando se de positivo, que estando Alfonso, como está, en mi pecho Alfonso á todas partes va conmigo.

Entra, y cierran las puertas: la música tocará un piano corto, y despues pasará á un alegro estrepitoso con el cual saldrá Alfonso mirando toda la escena, y dice luego.

Alf[onso]. No está en su cuarto; en vano para verla prestó el amor sus alas al cariño.

En vano entré por disfrutar su vista por la escusada puerta que dá al rio:

42. En el ejemplar que manejamos, $m i$.

43. En el ejemplar que manejamos, esperando, por errata. Seguimos la lectura de la otra edición impresa en Valencia, por José Ferrer de Orga, en 1813. 
no vivo sin Raquel, y es escusado que busque otro placer que su atractivo. No hay diversion alguna, no hay recreo, que pueda competir con sus hechizos; y así todo me cansa, y nada puede satisfacer el gusto, que concibo al mirarla: de tales perfecciones, tales gracias dotarla el cielo quiso, que las flores del campo congregadas al ver las flores que en su hermoso hechizo tan liberal sembró naturaleza digeron juntas al Abril florido, depón Abril el cetro de las flores, que de ellas el Imperio á Raquel dimos.

Dónde estará? la hora me asegura que estará distribuyendo beneficios, voy á verla á la Audiencia::- ${ }^{44}$ al disimulo es fuerza se sugete mi cariño.

Aqui la esperare...

Se sienta después de una pausa dice. [6]... De una tristeza

está mi corazon hoy poseido tan extraña, que todo me acobarda, todo me da pavor, aun á mi mismo.

Andante lúgubre que le llena de tristeza.

Yo mismo me acongojo, triste Alfonso! de qué tu sobresalto ha provenido! que tienes? qué te aflije? de los zelos tu corazón no sufre el cruel martirio, tus vasallos te adoran, y disfrutas de la hermosa Raquel el dulce hechizo. Ay Raquel! Ay Raquel! si tendrá acaso parte tu corazon en mis conflictos? parte tendrá, no hay duda, que en su pecho mi corazon existe, y es preciso que sienta el suyo, lo que el mio siente, y el suyo goze lo que goza el mio. Sentirá mi pesar; mi dolor siente, y no solo á Raquel mi afan limito, segun influye amor entre nosotros es capaz su retrato de sentirlo.

Música. Alfonso examina el retrato de Raquel, que estará á un lado colocado.

44. En el ejemplar que manejamos, Audioncia::, por errata que no se halla en la otra edición impresa en Valencia, por José Ferrer de Orga, en 1813. 
sus labios que á la rosa avergonzaban, en cándida azuzena convertidos, del pesar, que Raquel, por mi padece contribuyen también á dar indicios. El sol de su hermosura se ha eclipsado, y Alfonso sin sus luces confundido, entre las tristes sombras de las penas va dando de un abismo en otro abismo.

Música, y anda despavorido por la escena.

Ay triste Alfonso! miserable Alfonso! qué te va a suceder? responde, dilo? mas qué rumor es este, que en mi pecho

\section{Ruido dentro.}

un nuevo sobresalto ha introducido? qué ha de ser? el rumor del pretendiente que en tropel corre por lograr sumiso de mano de Raquel aquellas gracias, que en ella deposita mi cariño.

Mas mi temor es tal, tal mi rezelo, que del zéfiro blando hasta el suspiro me atemoriza. Alfonso, aquel esfuerzo, aquel valor que sobre el Berberisco tus sienes en las Navas de Tolosa, coronó de laureles infinitos, qué se ha hecho? de la Asia la memoria que eternizó tu nombre entre los siglos, cuando empuñó tu brazo la cuchilla para recuperar del Saladino

${ }^{[7]}$ la tierra misteriosa, de tu pecho no disipa el pavor que has concebido? el ánimo esforzado, la arrogancia que demostraste, cuando el fiero Sirio voló la mina en que tanto cristiano fue del ardid despojo, qué se hizo? por fin, dónde esta aquella constancia que en la santa ciudad mostró mi brio cuando el cruzado arnés pasó una flecha, en rojo humor el pecho vi teñido; y sin perder del Turco los alcances despreciando el dolor á un tiempo mismo, la flecha me quité con una mano, 
Dilo Alfonso, responde::: mas de nuevo parece que en la sala suena ruido. Si las guardias tal vez la turba atajan mas siguen al rumor confusos gritos; forzoso es acudir; sonido de armas ademas del rumor tambien percibo, vamos á ver la causa: qué es aquesto? Abre Alfonso de pronto las puertas, y salen á un tiempo
buyendo en dos filas los Castellanos con los aceros des-
nudos, y Raquel cae del Trono en los brazos de Alfonso.
Qué es aquesto Raquel? qué ha sucedido?

Raq[uel]. Recíbeme, mi bien, entre tus brazos.

Alf[onso]. Qué confusión es esta? mas qué miro? 255 dónde vais? por qué huis? que es lo que pasa? qué es esto, que la mano me he teñido en sangre? qué de horror! Ay Dios! me cubre? qué sangre es esta di? cielos divinos! tú traspasado el pecho?

Raq[uel]. Por amarte:::- 260

Alf[onso]. Quién tuvo atrevimiento? quién? sumisos demostrais á mis pies vuestra perfidia, ha viles! de este sitio huis? Guardias matadlos, si es bastante su vida á indemnizar tanto delito: prendedlos.

\section{Raq[uel]. Ay Alfonso!}

Alf[onso]. $\quad$ Raquel mia:::-

Raq[uel]. O qué caro me cuesta tu cariño!

Alf[onso]. Bien recelaba, ay triste! por qué causa traspasaron tu pecho? miento, el mio.

Raq[uel]. Por amarte.

Alf[onso]. yo os haré ver aleves fementidos el decoro, al respeto que se debe al que para mandar, Dios ha elegido; al que sus veces en la tierra egerce, al que reina por Dios; al que Dios mismo asi mismo reserva pedir cuentas; 
LAS OTRAS RAQUEL: EL DIÁLOGO TRÁGICO DE JOSÉ MARCH Y BORRÁS

y prescribe al vasallo, que atrevido no le obedece, ó falta á su decoro despues de su anatema, un cruel castigo: ${ }^{[8]}$ del castigo me encargo, y de tal modo perdido, dulce bien, he de cumplirlo, que si para vengarte no bastasen los tormentos, los potros, y suplicios, que inventó para afrenta del cristiano el sangriento rigor del gentílismo, he de inventar de nuevo otros mas fieros, mas inhumanos, bárbaros é impios. Por tu mano, por esa mano bella que afirmó tantas veces mi cariño, juro cumplir:::-

Raq[uel].

No jures::- considera

que del cielo dimana mi castigo, respeta sus decretos y si basta el tiempo que tu amor, subscribió al mio perdona de mi muerte el atentado, y admite Alfonso mi postrer suspiro.

Muere: la música toca un andante triste hasta la conclusión de la pieza y Alfonso queda recostado por un momento.

Alf[onso]. Murió Raquel, y Alfonso también muere: dónde hallaré consuelo en tal conflicto? ojos tristes, llorad, llorad á mares el fin funesto del trágico destino, de la infeliz Raquel, cuya hermosura aprisionados tuvo mis sentidos. Ay malogrado bien, que de tu muerte la causa principal mi amor ha sido! pero ya que no puedo darte vida, á la dulce memoria de tu hechizo vivir ofrezco del dolor cercado, ignorado, si es dable, de mi mismo, negado al mundo, en las incultas selvas entre las fieras siempre confundido, acabaré una vida::- Alfonso! Alfonso! sujeta a la razon tus desvaríos, en la triste Raquel, repara el fruto, la consecuencia ve de tu extravío. Legislador supremo, de tu mano conozco, que dimana su castigo. Detesto mis errores; y humillado 
mi corazón ${ }^{45}$, á tu poder resigno:

perdona mis ofensas, y protesto,

que los yerros de amor corrija el juicio.

\section{F I N.}

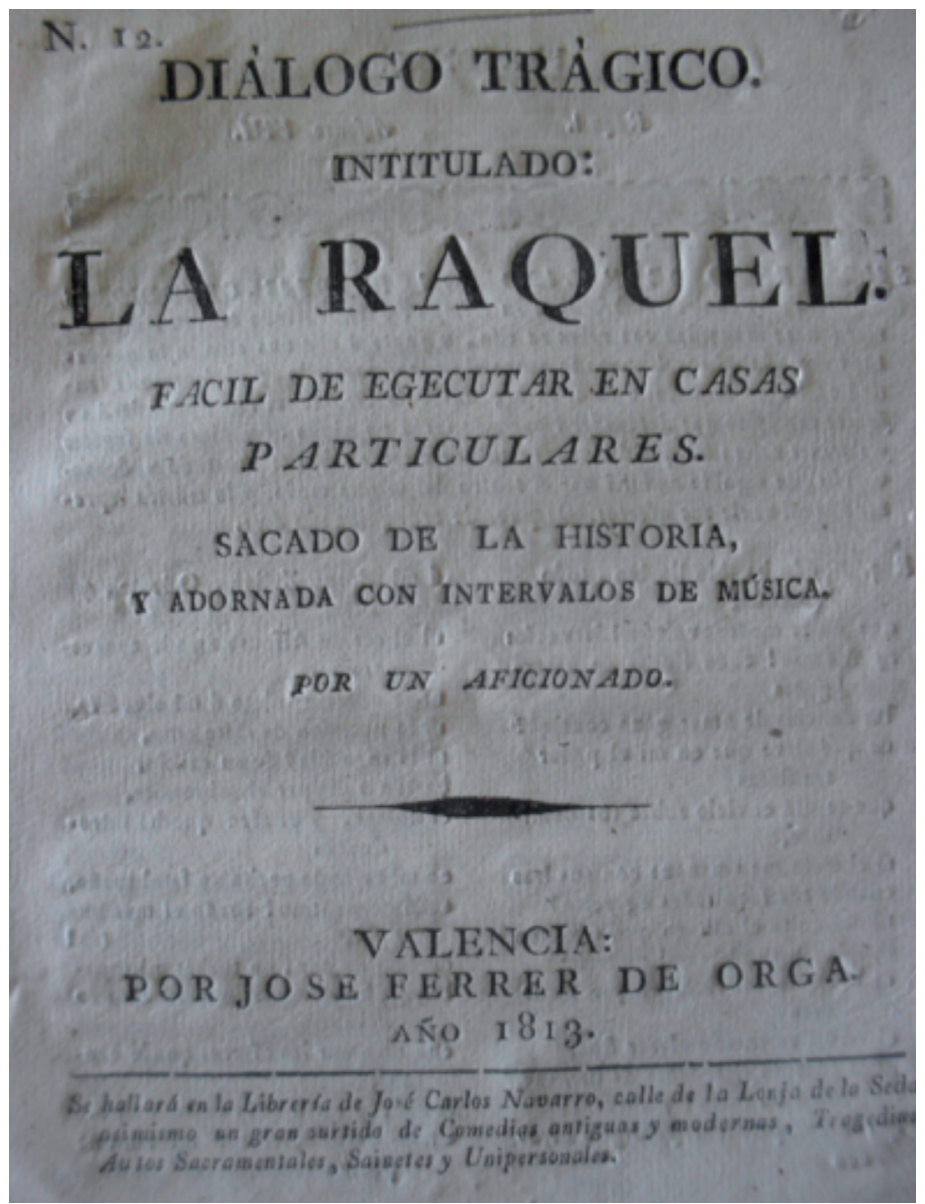

Portada de impresión de La Raquel, que sirve de base a nuestra edición.

45. En el ejemplar que manejamos, corzaon, por errata inexistente en la otra edición publicada en Valencia, por José Ferrer de Orga, en 1813. 


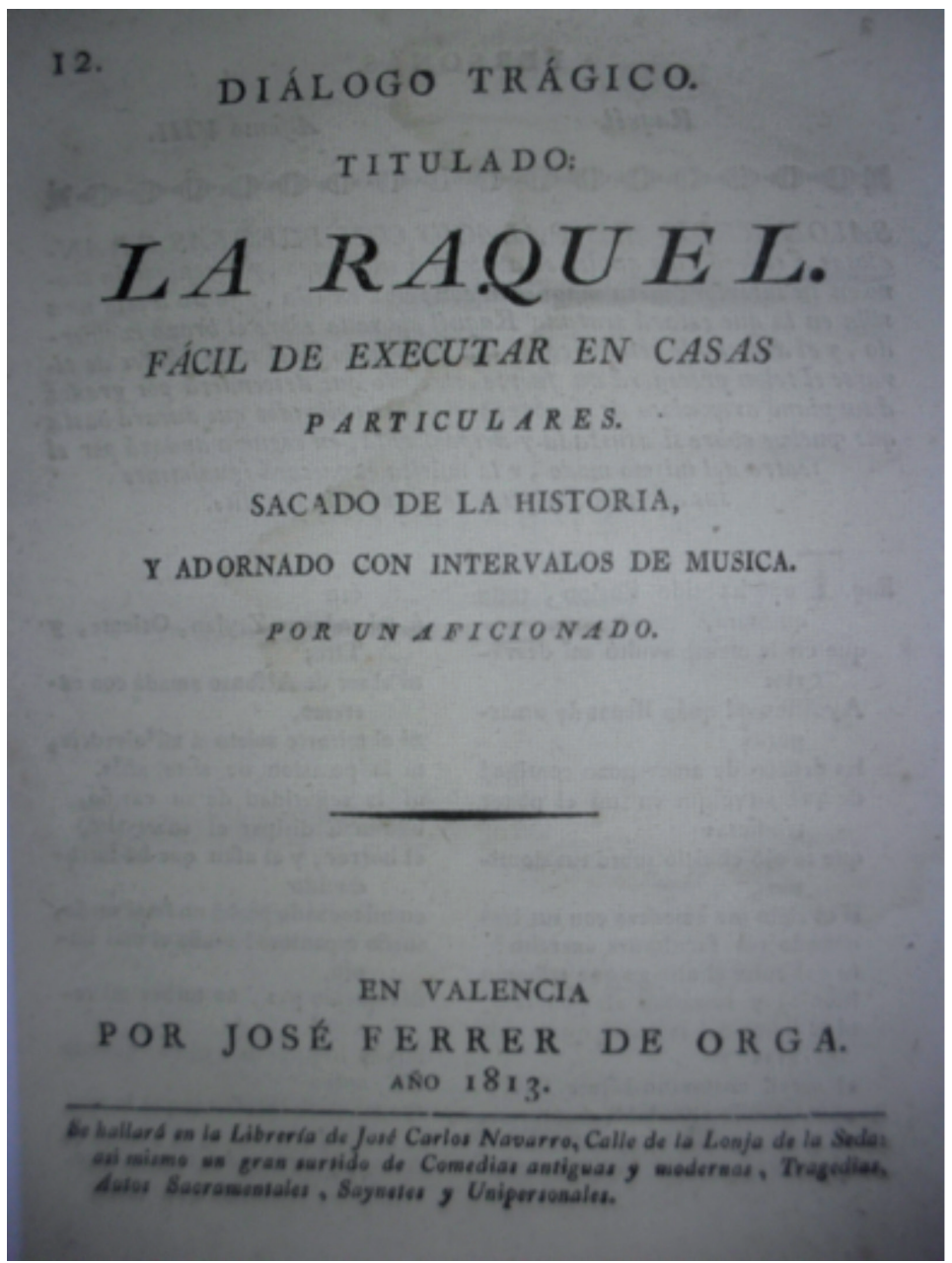

Portada de impresión valenciana de La Raquel que presenta abundantes variantes ortográficas con respecto al ejemplar que utilizamos como base para nuestra edición.

\section{BiBliografía}

\subsection{Ediciones}

Comella, Luciano Francisco. Melo-drama trágico en un acto Hercules y Deyanira. Compuesto por Don Luciano Francisco Comella. Barcelona: En la Oficina de Pablo Nadal, Calle del Torrente de Junqueras, Año de 1800. 
Comella, Luciano Francisco. Síquis y Cupido. Drama heroico en un acto. Por Don Luciano Francisco Comella. S. 1.: s. i., s. a.

CONCHA, José. El rencor mas inhumano de un pecho aleve y tirano, o La Condesa Jenovitz. Comedia en tres actos, con su Loa. Funcion facil de egecutarse en cualquier casa particular por estar toda arreglada para cinco Personas, y entre ellas una sola muger. Valencia: Imprenta de Ildefonso Mompié, 1816.

Enciso y Castrillón, Félix. Drama nuevo. Juanito y Coleta ó El Pleyto del Marquesado. Comedia en tres actos. Pensamiento frances del celebre Mr. Florian. Acomodado a nuestro teatro por D. F. M. E. y C. Pieza facil de executar en casas particulares. Madrid: s. i., Año 1799.

Esteve, Pablo. Comedia El amor filial. En dos actos. En verso. Fácil de executarse. Alcalá: s. i., Año de 1799.

EzQuerRa, Joaquín. «Don Alfonso VIII, Rey de Castilla, y Don Alfonso IX, Rey de León». En Retratos de los Reyes de España desde Atanarico hasta nuestro Católico Monarca Don Cárlos III (que Dios guarde). Segun las noticias y los Originales mas antiguos que se han hallado, con sus correspondientes Inscripciones y el sumario de la vida de cada Rey. Publicalos para instrucción de la juventud española Don Manuel Rodriguez, Académico Supernumerario de la Real Academia de S. Fernando, Grabador de láminas y sellos, tomo II. Madrid: Lorenzo de San Martín, 1788, pp. 265-268 (la historia de los amores de Alfonso VIII con la judía de Toledo aparece debatida en un apéndice final añadido titulado "La Judía de Toledo», e inserto entre las páginas 282 y 286).

Furmento, Antonio. Pequeña, y breve comedia, titulada, Lances de amor, desdén y celos. Fácil de executar en cualquier casa particular por no tener mas que tres personas. S. 1.: s. i., s. a.

GARCía DE LA HuerTa, Vicente. Raquel. Edición, introducción y notas de Jesús Cañas Murillo. Madrid: Bolchiro S. L., 2014.

García de la Huerta, Vicente. Teatro Completo. Edición crítica, introducción y notas de Jesús Cañas Murillo. Oviedo: Universidad de Oviedo, Instituto Feijoo de Estudios del Siglo XVIII, en prensa.

GonZÁlez, Manuel. El Entretenido, ó La brevedad sin sustancia. Escena unipersonal. Fácil de representarse en cualquier casa particular. Dispuesta en tres Jornadas, Entremés, dos Tonadillas y un Saynete. En CAÑAS Murillo, Jesús. «Una "escena unipersonal" entre dos siglos: El Entretenido, ó La brevedad sin sustancia, de Manuel González”. En su libro Cajón de sastre. Textos dispersos del setecientos español. Cáceres: Universidad de Extremadura (Textos UEx., 14), 2008, pp. 415-424.

IRIARTE, Tomás de. Guzmán el Bueno, Escena trágica unipersonal, con música en sus intervalos, compuestas ambas por D. Tomás de Iriarte para representarse en Cadiz Por el Señor Luis Navarro, primer Actor de la Compañía Cómica. Cádiz: D. Manuel Ximenez Carreño, Calle Ancha, Año de 1790.

IRIARTE, Tomás de. Guzmán el Bueno, Escena trágica unipersonal, con música en sus intervalos, compuestas ambas por D. Tomás de Iriarte para representarse en Cadiz Por el Señor Luis Navarro, primer Actor de la Compañia Cómica, en su Teatro original completo. Ed. Russell P. Sebold. Madrid: Cátedra, 2010, pp. 689 y 708. Letras Hispánicas, 654.

March y Borrás, José. Diálogo trágico. Intitulado La Raquel. Facil de egecutar en casas particulares. Sacado de la historia y adornado con intervalos de música. Por un aficionado. Valencia: José Ferrer de Orga, del año 1813. 
MARCH Y BorRás, José. Diálogo trágico titulado La Raquel: facil de executar en casas particulares, sacado de la historia y adornada con intervalos de música por un aficionado. Salamanca: Imprenta de Francisco Tóxar, s. a.

March y Borrás, José. Diálogo trágico. Titulado: La Raquel. Fácil de executar en casas particulares. Sacado de la historia y adornado con intervalos de musica. Por un aficionado. Valencia: José Ferrer de Orga, del año 1813.

NiPHo, Francisco Mariano. Pigmalion. Monólogo patético, traducido y puesto en verso, por D. F. M. N. Valencia: José Ferrer de Orga, 1813.

Padre e hijo. Comedia en un acto traducida del francés. Madrid: Imprenta de D. José María Repullés, 1837.

Rey, Fermín del. Policena. Scena trágica Representada por la señora Catalina Fabiani Munteis en el coliseo de la Cruz en el mes de febrero de este año de 1794, Escrita por Fermin del Rey, primer apuntador de la Compañía de Manuel Martínez. Madrid: en la Imprenta Real, en 1794.

Rodríguez de ARellano y El ARCo, Vicente. El domingo, ó el cochero, Escena sola, monólogo, soliloquio, lamentacion, declamacion, ó llamese como quisiere, que á su autor le importa poco el nombre. Por D. Vicente Rodriguez de Arellano y El Arco. Valencia: Imprenta de Estévan, Año 1818.

Sala y SAURI, Eduardo. Un deudor de viaje ó Don Robreño hecho comico. Fin de fiesta. En Cañas Murillo, Jesús. "Un fin de fiesta del siglo XIX: Un deudor de viaje ó Don Robreño becho comico, de Eduardo Sala y Sauri». Cuadernos de Ilustración y Romanticismo. Revista del Grupo de Estudios del Siglo XVIII, 2007, n. ${ }^{\circ} 15$, pp. 239-270 (también recogido en su libro Cajón de sastre. Textos dispersos del setecientos español. Cáceres: Universidad de Extremadura, 2008, pp. 459-489. Textos UEx., 14).

TÓJAR, Francisco de. La Filósofa por amor o Cartas de dos amantes apasionados y virtuosos. Edición de Joaquín Álvarez Barrientos. Cádiz: Universidad de Cádiz, 1995.

Las tramas de Garulla. Valencia: Ildefonso Mompié, 1822.

Zavala y Zamora, Gaspar. El día de campo. En CaÑas Murillo, Jesús. "Teatro de mayorías para deleite de minorías: El día de campo, de Gaspar Zavala y Zamora». En CAÑAS Murillo, Jesús; Grande QuejIGo, Francisco Javier y Roso Díaz, José (eds.). Literatura Popular e Identidad Cultural. Estudios sobre Folclore, Literatura y Cultura Populares en el mundo occidental. Cáceres: Universidad de Extremadura, 2010, pp. 235-257.

\subsection{Estudios}

Aguilar Piñal, Francisco. «March y Borrás (José)». En su Bibliografía de Autores Españoles del siglo XVIII, V, L-M. Madrid: CSIC, 1989, p. 399.

Aguilar PiÑAl, Francisco. «Tojar (Francisco de)». En su Bibliografía de Autores Españoles del siglo XVIII, VIII, T-Z. Madrid: CSIC, 1995, pp. 60-61.

Álvarez Franco, Malén. "El día de campo en el teatro popular de la Ilustración: Gaspar Zavala y Zamora». En CAÑas Murillo, Jesús; Grande QuejIGo, Francisco Javier y Roso DíAZ, José (eds.). Literatura Popular e Identidad Cultural. Estudios sobre Folclore, Literatura y Cultura Populares en el mundo occidental. Cáceres: Universidad de Extremadura, 2010, pp. 229-234.

Balbás CruZ, Juan Antonio. Castellonenses Ilustres. Apuntes biográficos. Castellón de la Plana: Tipografía de José Armengot, 1883 (sobre José March y Borrás, pp. 108-110). 
CaÑas Murillo, Jesús. "Tipología de los personajes en las tragedias de Vicente García de la Huerta». En Simposio Internacional "Vicente García de la Huerta» (1787-1987). En CAÑas Murillo, Jesús y Lama, Miguel Ángel (ed.). Revista de Estudios Extremeños, mayoagosto de 1988a, XLIV, II. Badajoz: Servicio de Publicaciones de la Excma. Diputación Provincial, pp. 349-377.

CaÑas Murillo, Jesús. "Las paces de los reyes y Judía de Toledo, de Lope de Vega, un primer preludio de Raquel». Anuario de Estudios Filológicos, 1988b, XI, pp. 59-81.

CAÑas Murillo, Jesús. "Sobre la poética de la tragedia neoclásica española». Revista de Filología y Lingüistica de la Universidad de Costa Rica, enero-junio 1999, XXV, 1, pp. 115-131.

CaÑas Murillo, Jesús. «Raquel, de Vicente García de la Huerta, en la tragedia neoclásica española». Anuario de Estudios Filológicos, 2000, XXIII, pp. 9-36.

CAÑas Murillo, Jesús. "García de la Huerta y la tragedia neoclásica». En HuerTa Calvo, Javier (dir.). Historia del teatro español. Madrid: Gredos, 2003a, 2 vols., vol. II. Del Siglo XVIII a la época actual, coordinado por Fernando Doménech Rico y Emilio Peral Vega, pp. 1577-1602.

CAÑAS MuRILLO, Jesús, «La tragedia neoclásica española». En Literatura Española en los siglos XVIII $y$ XIX, área coordinada por Alberto Romero Ferrer y Joaquín Álvarez Barrientos, publicado en internet, Liceus, El portal de las Humanidades, www.liceus.com/cgi-bin/ aco/lit/01/0112.asp\#xviii, 2003b.

CaÑas Murillo, Jesús. "Teatro celebrativo en honor de Carlos III: El Nuevo Apolo y Minerva". En su libro Cajón de sastre. Textos dispersos del setecientos español. Textos UEx., 14. Cáceres: Universidad de Extremadura, 2008, pp. 401-414.

CAÑas Murillo, Jesús. "Una "escena unipersonal” entre dos siglos: El Entretenido, ó La brevedad sin sustancia, de Manuel González". En su libro Cajón de sastre. Textos dispersos del setecientos español. Textos UEx., 14. Cáceres: Universidad de Extremadura, 2008, pp. $415-424$.

CAÑas Murillo, Jesús. «Teatro neoclásico para representaciones particulares: Polixêna, tragedia en un acto, fácil de executarse». Anuario de Estudios Filológicos, 2010a, XXXIII, pp. 39-63.

CAÑas Murillo, Jesús. "Teatro de mayorías para deleite de minorías: El día de campo, de Gaspar Zavala y Zamora». En CaÑas Murillo, Jesús; Grande QuejIGo, Francisco Javier y Roso Díaz, José (eds.). Literatura Popular e Identidad Cultural. Estudios sobre Folclore, Literatura y Cultura Populares en el mundo occidental. Cáceres: Universidad de Extremadura, 2010b, pp. 235-257.

CaÑas Murillo, Jesús. «El poderoso como personaje y como tema en la tragedia neoclásica española». Cuadernos de Ilustración y Romanticismo. Revista Digital del Grupo de Estudios del Siglo XVIII 19, Teatro ilustrado y modernidad escénica (2013), pp. 85-109 (http://revistas.uca.es/index.php/cir/article/view/1835).

CAÑaS MuRILLO, Jesús. «El tema de la monarquía entre la comedia nueva y la tragedia neoclásica española: la Ilustración frente al Barroco». Annali. Sezione Romanza, 2014a, LVI, 1, Nápoles: Universidad de Nápoles L'Orientale (Italia), L'Orientale Editrice, pp. 97-126.

CaÑas Murillo, Jesús. "Vicente García de la Huerta y los Retratos de los Reyes de España: un problema bibliográfico y una aclaración». eHumanista. Journal of Iberian Studies, 27, "Siglo ilustrado y siglo filosófico": cultura y letras hispánicas en el siglo XVIII». QUINZIANO, Franco (ed.). University of California, Santa Barbara, California (Estados Unidos de 
América), 2014b, pp. 89-168. (http://www.ehumanista.ucsb.edu/volumes/volume_27/ pdf/special\%20volume/7\%20ehum27.canas.pdf).

CaÑas MuRiLlo, Jesús. «Un proyecto editorial: Los Retratos de los Reyes de España, de Manuel Rodríguez y Vicente García de la Huerta». En CaÑas Murillo, Jesús; Grande QuejIGO, Francisco Javier y Roso DíAz, José (eds.). Vicente García de la Huerta y su obra (17341787). Biblioteca Filológica Hispana, 170. Madrid: Visor Libros, 2015, pp. 187-290.

Cañas Murillo, Jesús; Lama, Miguel Ángel y Roso Díaz, José (eds.). Vicente García de la Huerta y su obra (1734-1787). Biblioteca Filológica Hispana, 170. Madrid: Visor Libros, 2015.

CaÑas Murillo, Jesús. La tragedia neoclásica española. Madrid: Ediciones Liceus, 2017. Aprendizaje Express, 1.

HERRERA NAVARRO, Jerónimo: «March y Borrás, José (?-1796)». En Catálogo de Autores Teatrales del Siglo XVIII. Madrid: Fundación Universitaria Española, 1993, p. 285.

Huerta Calvo, Javier (ed.). Historia del teatro breve en España. Madrid-Frankfurt: Iberoamericana-Vervuert, 2008.

Martín LARGO, José Ramón. La judía de Toledo, desde Lope de Vega hasta Franz Grillparzer. Prólogo de Ángel Gómez Moreno. Madrid: Brand Editorial, 2000.

Menéndez Pelayo, Marcelino. "Las Paces de los Reyes y Judia de Toledo». En sus Estudios sobre el teatro de Lope de Vega. Edición de Enrique Sánchez Reyes. Santander: CSIC, 1949, pp. 79-106.

PASTOR Fuster, Justo. Biblioteca Valenciana de los Escritores que florecieron hasta nuestros dias. Con adiciones y enmiendas a la de D. Vicente Ximeno. Valencia, 1827-1830, 2 vols. (sobre José March y Borrás, tomo II, p. 171).

Sala-VAllDaURA, Josep Maria. Caminos del teatro breve del siglo XVIII. Lérida: Universidad de Lérida-Pagès Editors, 2010.

SERRANO Y MORAles, José Enrique. «Ferrer de Orga-José». En su Reseña histórica en forma de Diccionario de las Imprentas que han existido en Valencia desde la introducción del arte tipográfico en España hasta el año 1868. Estudio introductorio de Nicolás Bas Martín. Valencia: Ayuntamiento de Valencia, 2000, pp. 164-176.

SUBIRÁ, Jose. "Un "melólogo" curioso y una "introducción” a otro melólogo: La escena trágica "Policena"». Revista de la Biblioteca. Archivo y Museo del Ayuntamiento de Madrid, año V (octubre de 1928), n. ${ }^{\circ} \mathrm{XX}$, pp. 360-364. 
